\title{
Üniversite Yayıncıllı̆̆ı ve Muallim Doktor Besim Ömer Bey
}

\section{University Publications and Prof.Dr.med. Besim Ömer Bey}

Besim Ömer, Çocuk Büyütmek, yay.haz. Haluk Perk, İstanbul, Sağlık Bilimleri Üniversitesi yay., 2019, (ciltli, 23,5x31,5 cm., 123 s., tıpkıbasım, çeviriyazı, sadeleştirme, şekil, dizin)

ISBN 978-605-80777-0-6

\section{Doktor Besim Ömer Paşa, Doğururken ve Doğurduktan Sonra} (H. 1320/M. 1902-1903), yay.haz. Türkmen Töreli, İzmir, Dokuz Eylül Üniversitesi yay., 2014 (21x30 cm., x+307 s., tıpkıbasım [147 s.], çeviriyazı) ISBN 978-975-441-424-0

\section{Şeref Etker ${ }^{1}$ (1)}

\section{'Dr., İstanbul, Türkiye}

ORCID: Ş. E. 0000-0001-6966-8816

Sorumlu yazar/Corresponding author:

Şeref Etker,

Istanbul, Türkiye

E-posta/E-mail: serefetker@gmail.com

Başvuru/Submitted: 26.01.2021 • Kabul/Accepted: 14.05.2021 • Online yayın / Published online: 05.07.2021

Atıf/Citation: Etker, Şeref."Üniversite Yayınclığı ve Muallim Doktor Besim Ömer Bey." Osmanlı Bilimi Araștırmaları 22, 2 (2021): 371 -384. https://doi.org/10.26650/oba.868510 


\section{I. Çocuk Büyütmek}

Tabip Kolağası Besim Ömer Efendi, Exposition Universelle olarak tanınan uluslararası serginin açıldığı 1889 yılında Paris'de eğitim görmektedir. ${ }^{1}$ Aynı tarihlerde, tütün karşıtlarının yine Paris'de toplanan kongresine (Congrès international contre l'Abus de Tabac) katılır ve organizasyonun başkan yardımcılığını yapar. Kongrede "Tütün ve İstanbul yangınları" (Le Tabac et l'Incendie à Constantinople) ${ }^{2}$ ve “Türkiye'de tütün kullanımı" (Le Nicotisme en Turquie) $)^{3}$ konularında iki konuşma yapan Besim Ömer (Akalın), yurda dönüşünde çocuk bakımı ve halk sağlığına ilişkin kitaplar yayımlayacaktır. ${ }^{4}$ Bunlardan biri Çocuk Büyütmek' dir.

Dr. Besim Ömer'in Çocuk Büyütmek kitabının elyazması bulunarak tıpkıbasımı, diliçi çevirisi ve sadeleştirilmiş metniyle birlikte yeni bir basımı yapılmıştır. Yazmalara özgü bibliyografik künyesi verilmemiş olmakla birlikte, tıpkıbasımının bire bir (1:1) ölçeğinde yapıldığını varsayabiliriz. Yeni basımın girişinde, Besim Ömer Akalın'ın Çocuk Büyütmek adlı (kayıp) kitabının yazılışıyla ilgili bir anısı aktarılmıştr. Bunun dışında elimizdeki yayının hazırlanışı, çeviri ve sadeleştirme yöntemi konusunda bir açıklama yapılmamıştır. Örneğin, tıbbi metinlerde ırzâ veya 1rza' (emzirme; ırzahane: kreş) yazımı kullanılmakta iken, ${ }^{5}$ bu çeviride neden irza' ${ }^{6}$ yazımının seçildiği anlaşılamamaktadır. ${ }^{6}$

1 Kolağası rütbesindeki subaylara 'Efendi' denilmektedir. Dönemin Fransızca yayınlarda ise Dr. Besim Ömer'in unvanı 'Bey'dir [Tabip Kolağası: médecin-major de deuxième classe]. Uluslararası Paris Sergisi ve İbrahim Edhem'in (Dirvana) sergi izlenimleri için, bkz. 1889 Paris Umûmî Sergisi, ed. Fahrettin Gün, yay. haz. Akile Çelik (İstanbul, TBMM Saraylar Dairesi Başkanlığı, 2010).

2 Société française contre l'Abus du Tabac, [Le Premier] Congrès international contre l'Abus du Tabac [Paris, 8 - 11 Juillet 1889] (Paris, Félix Alcan, 1890), 46-47. M. Omer-Bey, (médecin-major, professeur à la Faculté de Médecine de Constantinople), "Le Tabac et l'Incendie à Constantinople": Après une description poétique de Constantinople, l’honorable Vice Président (M. le Dr. Bessim Omer Bey), décrit la terreur qui parcourt la ville à l'annonce d'un incendie, qui prend presque toujours une extension considérable: "Lemotincendie, dit-il, à Constantinople, presquetous les malheurspourlapopulation, etlecri 'Janghen [Yangin] var' (au feu) est un cri terrifiant, qui fait trembler les plus courageux comme l'annonce d'un châtiment d'Allah !" Le plus souvent les causes premières du fléau dévastateur est une cigarette allumée, jetée imprudemment par les fenêtres et tombée entre les planches qui couvrent l'extérieur des maisons construites complètement en bois, ou bien encore des chibouks et des narghilés renverés sur les tapis et sur les planchers. Le Dr. Bessim Omer explique comment se pratique la contrebande en Turquie, les maux qui en résultent, les crime qui en sont la conséquence. Il termine en ces termes sa communication fort intérresante: "Ce n'est pas par la répression qu'on arrivera à débarrasser le monde de l'usage immodéré du tabac et, par conséquent, de la contrebande: la douceur et la persuasion viendront plus facilement à bout: c'est donc ici que commence le rôle de la noble Société contre l'abus du tabac, en agissant particulièrement sur l'intelligence de l'enfant aux premières heures de la culture qu'elle reçoit par la famille et par l'école communale."

3 Bessim Omer, "Le Nicotisme en Turquie," Journal de la Société contre l'Abus du Tabac 18, 1 (janvier 1894): 18-20; 18, 2 (février 1894): 38-41; 18, 3 (mars 1894): 60-64.

4 Dr. Besim Ömer, 1889'da Paris'de Hôtel-Dieu hastanesinde toplanan uluslararası Hipnotizma Kongresine de katılmıştır, bkz. Premier Congrès international de l'Hypnotisme expérimental et théraputique, tenu à l'HôtelDieu de Paris, du 8 au 12 Août 1889, ed. Edgar Bérillon (Paris: Octave Doin, 1889), 19 (Membres adhérents). Ayrica bkz., dn. 33.

5 Krş., H. Nil Sarı, A. Iraz Savun, "Türk Tarihinde Acizlerin Korunmasına Kısa Bir Bakış II; Kimsesiz Süt Çocuklarının Örnek Yuvası 'Dârü'l Irzâ'," Ttp Tarihi Araştırmaları 5 (1993): 34-51; Hürü Sağlam Tekir, "Osmanlıda Kimsesiz ve Yoksul Çocuklara Anne Şefkati: Irzahane," History Studies 12, 6 (Aralık 2020): 3127-3146.

6 Sağlık Bilimleri Üniversitesi'nin yeni bir yayınında ise, Dr. Besim Ömer'in eserleri arasındaki Darülâceze 
Çocuk Büyütmek kitapçığının 1889-1894 tarihleri arasında yazılmış olabileceği önerilmektedir. ${ }^{7}$ Besim Ömer elyazmasında, katıldığı Exposition universelle için 'iki sene evvel küşad edilen sergi’ dedikten sonra (s. 20), '1890 sene-i miladiyesinde Paris'de küşad olunan sergi-yi umumi’ye (s. 55) değinerek ‘risaleciğinin' yazılış tarihini 1892 olarak vermiş olmaktadır. Dr. Besim Ömer'in Paris’den 1891 yılı sonunda dönmüş ve "Mekteb-i Tıbbiye-i Şahane'ye [Askeri Tıbbiye] Fenn-i Vilade Muallimi [Doğum Bilgisi/Obstetrik Profesörü]" olarak atanmış olması bu tarihlendirmeyi desteklemektedir.
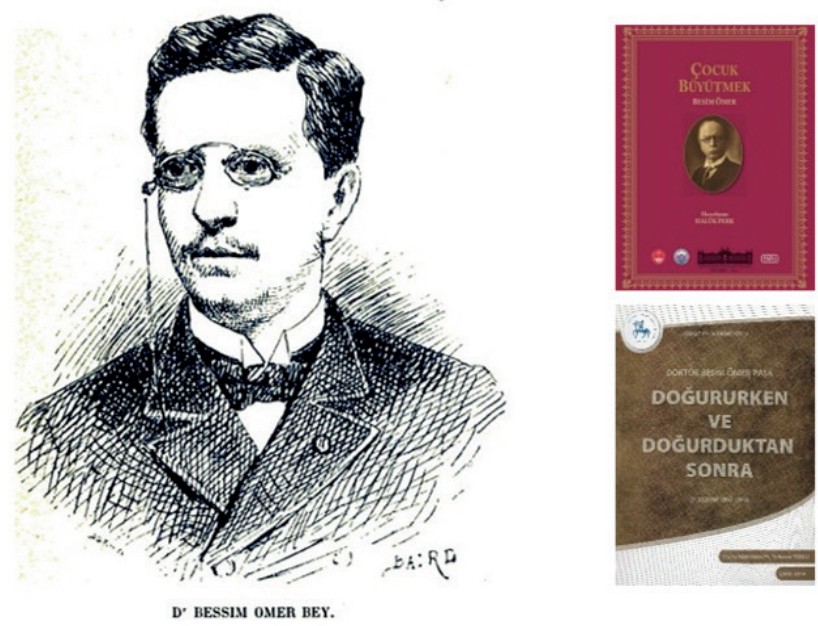

Besim Ömer Akalın (Paris, 1889) ${ }^{8}$

Çocuk Büyütmek yazması değerlendirilirken öncelikle belirtilmesi gereken metnin bir çeviri olduğudur. Besim Ömer, Fransız hekimler Dr. Alfred P.V. Auvard (1855-1942) ve Dr. Henri Pingat (1862-1917) tarafından hazırlanan Considérations sur l'Hygiène infantile ancienne et moderne (Maillot, Berceau et Biberon à travers les Âges) ${ }^{9}$ adlı kitabı eklerle Türkçeye çevirmiştir. Yazmanın tam başlığı: Çocuk Büyütmek (Kadimden Beri Müstamel Kundak ve Beşik ile Emzik Şişelerine Dair [Musavver Risale]) olup, Auvert ile Pingat'nin anılan kitabının başlığından uyarlanmıştır. Besim Ömer Bey'in çeviriye katkısı birkaç paragraf ve çizim olmuştur. ${ }^{10}$ Yeni yayımın girişinde, “Alfred [Auvard] ve Pingat'in Eski

Irzâhanesi (İstanbul, Ahmed İhsan Matbaası, 1319) kitabının adında ırzâ yazımı görülmektedir, bkz. Besim Ömer, Nevsâl-i Âfiyet, c. I, yay.haz. Ahmet Zeki İzgöer (İstanbul, Sağlık Bilimleri Üniversitesi yay, 2020), xxiii \# 38.

7 Nil Sarı, “Besim Ömer Paşa'nın 'Çocuk Büyütmek, Eskiden Beri Kullanılan Kundak, Beşik ve Emzik Şişelerine Dair Resimli Kitapçık’ İsimli El Yazması,” Besim Ömer, Çocuk Büyütmek, yay.haz. Haluk Perk (İstanbul, Sağlık Bilimleri Üniversitesi yay., 2019) içinde, 6-11.

8 Congrès international contre l'Abus du Tabac (Paris: Félix Alcan, 1890), 54 (çizim: W. Baird).

9 Alfred Auvard ve Henri Pingat, Considérations sur l'Hygiène infantile ancienne et moderne (Maillot, Berceau et Biberon à travers les Âges) (Paris: G. Rongier \& Cie, 1889), 76 p., 1 vignette, 85 fig.

10 Dr. Besim Ömer Akalın'ın daha sonra Çocuk Büyütmek adıyla yayımladığı iki kitap içerik olarak elyazmasından 
ve Modern Çocuk Sağllğı (Hygiène infantile ancienne et moderne) isimli risalelerden yararlandığını [Besim Ömer] kendisi bildiriyor" denilmiş olması (s. 8), ${ }^{11}$ Besim Ömer'in hazırladığı resimli kitapçığın Auvard ve Pingat'nin adıgeçen kitaplarıyla karşılaştırılmamış olduğunu düşündürmektedir. İrdelendiğinde, Çocuk Büyütmek adlı kitabın elyazmasında Türkiye'den verilen örneklerin bile Auvard ve Pingat'nin kitabından alındığı görülecektir:

Auvert \& Pingat, s. 8-9

"Dans la Turquie d'Asie les musulmans, par example, enveloppent fortement l'enfant depuis les pieds jusqu'au cou avec un long bandage de deux à trois mètres: ils appliquent les bras le long du corps. Plusieurs fois par jour on enlève cet appareil pour les soins de propreté, mais on se hâte vite de le remettre. Parfois la constriction du petit corps est si grande que la face est toute cyanosée, indice certain d'une certaine gêne de circulation. Les musulmans ne s'en effrayent pas, désirant un certaine constriction afin que leurs enfants deviennent raides et droits 'comme des bougies', a-t-on dit justement."

Çocuk Büyütmek, Yazma, s. 15 [106]

"Anadolu' da çocuklar iki-üç metre uzunluğunda bir bez ile boyundan ayaklara kadar sarılır ve kollar vücuda bitişdirilir. Günde birçok defalar li-ecli’t-tathîr kundak çözülür ise de hemân der-akab yine bağlanır. Bazen çocuk o kadar ziyâde sarılır ki, yüzü ihtinâk alâmeti olmak üzere mavileşir ise de ebeveyn bundan aslâ telâş etmezler. Zîrâ çocuklarının 'mum gibi doğru' olmasını arzû ederler."

Auvert \& Pingat, s. 41-42

"Le berceau turc, par exemple, est un berceau oscillant, peu élevé. Ce qu'il y a de curieux, c'est que toujours il est percé d'un trou où s'adapte un vase dans lequel tombent les déjections." (fig. 38. Berceau turc)

\section{Çocuk Büyütmek, Yazma, s. 61 [60]}

"Ez-cümle Türk beşiği sallantılı ve az mürtefi“ olmağla berâber, asıl tuhafı dâima altının delikli olması ve buradan bir oturak sarkmasıdır.” (s. 63 [58] Şekil 47. İstanbul'da beynelahali müstamel beşik. $)^{12}$

farklıdır: Besim Ömer Paşa, Çocuk Büyütmek (İstanbul: Matbaa-i Ahmed İhsan, 1320/1904) 116 s.; Doktor Besim Ömer, Çocuk Büyütmek (İstanbul: Kanaat Kütüphanesi, Yeni Matbaa, 1341/1925), 226 s. Bkz. dn.19.

11 "Risalenin mehazı: 1889 senesi Paris Umumi Sergisini ziyaretimde ahz eylediğim notlar ve vilayat-1 şahaneden mevrud malumat ve M. [Gustave-Joseph] Witkowski'nin Tarih-i Viladat [Histoire des Accouchements chez tous les Peuples, 1887] ve Dr. [Paul] Eram'ın Şark'da Viladat [Quelques Considérations pratiques sur les Accouchements en Orient, 1860] nam kitabları ile Mrs. Auvard et Pingat ismindeki zevatın risalesidir." Sihhatnüma-i Nevzatdan Kundak-Beşik-Emzik, tab'-1 evvel (İstanbul, Alem Matbaası, Ahmed İhsan ve Şürekas1, 1312/1896), 4. Besim Ömer, ayrıca Jules Rouvier'nin 'Première enfance' (sic) [Hygiène de la première Enfance, 1889] adlı kitabını da kaynak göstermiştir (s. 73).

12 Besim Ömer, 'Milli beşiğimiz' hakkındaki görüşünü şöyle açıklamıştır: " "Habishane-i etfal'den başka bir şey olmayan ve çok defa tahtakehlesi [tahtakurusu, beşik biti], pire ve sair muziyata karargah olan beşiklerimizin bütün fenalıklarını uzun uzadıya sayub dökemiyeceğiz; zaten dar ve pek alçak olan bu beşiklerde çocuğun üzeri 


\section{Besim Ömer'in katkıları}

Dr. Besim Ömer'in Auvard ve Pingat'den yaptığı çeviriye katkıları önemli ve özgündür. Bu bölümlerin üzerinde ayrıca durulması gerekir:

(i) “İstanbul'da kullanılmakda olan kundak takımı” Kundak bölümünün sonuna eklenmiştir (Yazma, s. 28-34 [85-97]). Çizim için boşluklar bırakılmıştır; çizim yoktur.

(ii) 'Her ne kadar Doktor [Paul] Eram'ın sözlerini mâzî-yi naklî sigalarıyla nakletmiş isek de yine tabib-i mumâileyhi tasdîkan biz de şunu ilave edelim ki: Amasya ve civarında öllükcülerin satmakda oldukları öllük...” (Yazma, s. 49-52 [69-72]).

(iii) "Memalik-i şahane'de orta halde ailelere mensub kadınlar çocuklarına ya bizzât meme verirler veyahud emzik ile emzirirler. $\mathrm{Si}^{`} \mathrm{a}-\mathrm{i}$ halde olanlar ise südnine tedârik eylerler. Kur'ân-1 azîmü'ş-şân' da Sûre-i Bakara'da... (Yazma, s. 81-82 [39-40]).

(iv) Besim Ömer'in 'Emzik' bölümünün sonuna (yazma, s. 89-99 [23-32]) yaptığ1 ekin kaynağını, yine 1892 yılında, “'Emzirme’ nâmıyla yazdığımız bir makale” olarak göstermektedir (Yazma, s. 94 [27]). ${ }^{13}$

Ayrıca, "Tekne biçimindeki eski beşikler bizim köylerimizde bile görülmekdedir" (Yazma, s. 53-54 [67-68]), gibi tek cümlelik katkıları vardır. Benzer katkılara diğer baskılarda da yer verilmiştir: örneğin, “Bizde bazı ailelerin kullandıkları ve 'faska' namını verdikleri bağı kullanmamalıdır; çünki, karnı, göğsün aşağısını ezüb sıkışdırır."14

\section{Çizim katkıları}

\section{Çocuk Büyütmek,} Yazma:

s. 50 [71] Şekil 29 : Amasya ve civarında müstamel uğursuz beşik.

s. 64 [57] Şekil 48: Tahta salıncak. ${ }^{15}$

Şekil 49: İstanbul'da müstamel sübek. ${ }^{16}$

sımsıkı sarılub örtülür, beşiğin direği üstüne bir yorgan atılır... Bir de bizim beşiklerde mini mini "bağırdak" namını alan bitmez tükenmez bağlarla sarılır ki, bu sarılma hep beşiğin ziyade sallanışında çocuğun düşmemesi ve bir de ayaklarının hareketile mahud 'sübek'in yerinden oynamaması içündür. İnsaf etmeliyiz, böyle bir beşik mezar ve 'darülbevar' [cehennem] tavsifinden başka neye layıkdır ?” Çocuk Büyütmek, 1320/1904, s. 39-41 (Şekil 42).

13 Doktor Besim Ömer, "Emzirme (Irza‘-i Sınai) ve Emzirme Şişeleri," Servet-i Fünun 57 (2 Nisan 1308/14 Nisan 1892): 68-72 (Emzirme, Konstantiniyye [İstanbul], Matbaa-i Ahmed İhsan, 1309/1893, 9x12 cm., 32 s.). Ayrıca, Doktor Besim Ömer, “Meme Virme," Servet-i Fünun 66 (4 Haziran 1308/16 Haziran 1892): 215, 218-219.

14 Besim Ömer, Çocuk Büyütmek, 1320/1904, 32.

15 'Salıncak : Berceau turc suspendu,' Sihhatnüma-i Nevzatdan Kundak-Beşik-Emzik, 28 (Şekil 31).

16 Yeni basımın girişinde "Sıhhatnüma-i Nevzatdan isimli baskı kitabın yazıları ve resimleri el yazması Çocuk Büyütmek kitabından yer yer farklılık göster[diği]” belirtilmiş, fakat yalnız resimlerden örnekler verilmiştir (s. 


\section{s. 65 [56] Şekil 50: Asma Osmanlı Beşiği. ${ }^{17}$}

s. 74 [47] Şekil 67: İstanbul'da müstamel çocuk arabası.

Şekil 68 : İstanbul'da müstamel çocuk iskemlesi.

\section{'Gurreden mamul desti' : Çocuk Büyütmek'de çeviri hataları}

Çocuk Büyütmek adlı yazmanın diliçi çevirisinde yazım hataları, eksik/yanlış okumalar ve yakıştırmalar görülmektedir. Girişteki 'çocuk yetiştirme fenni ve sanatı (püer-i kültür)' biçiminde yazılan tanıma bakılırsa Fransızca puériculture teriminin anlamı olmayan bir Osmanlıca tamlamaya dönüştüğü görülür (s. 12). ${ }^{18}$ Besim Ömer 'çocuk büyütmek (yetiştirmek)' terimini püerikültür karşılığında kullanmıştır. ${ }^{19}$

\section{Yazma :}

s. 5 [116] devam-1 ömr ü izdiyad-ı hayriyeyi... cümlesinde aşağıda köşeli parantez içinde verilen cümle çevirilmemiştir.

\section{Doğrusu: devam-1 ömr ü izdiyad-1 [şevket ü şan-ı hazret-i mülükane hakkında varid-i} zeban-ı bendeganem olan davat-1] hayriye-i... olmalıdır.

9-11). Besim Ömer'in bu metne katkılarından biri 'Türk beşiği’ ve sübek konusundadır: “Alçak beşikle ayaklı beşik arasında diğer neviler de bulunur ki, şekil ve hacmi pek muhtelifdir. Evvel-emirde, bu meyanda İstanbul'da kullanılub sallantılı ve az mürtefi olan ve Avrupalılar nezdinde 'Türk beşiği' ismile maruf bulunan, tahtadan, az çok kafesli ve altından delikli beşiği zikrederiz. Bunların tezyinat cihetile envaı vardır. Her yerde müstamel alçak beşiklerle İstanbul'da kullanılan beşiklerin farkı: alt tarafda çocuğun kıçı tesadüf edecek mahalde 'beşik oturağı'nın müruruna mahsus müdevver bir delik bulunmasıdır. Bu nevi beşiklerin mütemmimatından olan ve bir ucu lazımlığa diğer ucu da çocuğun uzv-1 tenasülüne tatbik olunan 'sübek' isminde zükur ve inas içün muhtelif boruların bu sırada zikrini münasib gördüm. Sübekler sırçadan yahud tahtadan satılmakda ise de tahta nevi bevl ile temasa geldikde pek fena kokduğundan nadiren kullanılur. Bazen sübek yerine portakal, limon, taflan yaprakları gibi katı yapraklar istimal ediyorlar; sübeklerin bir ucunu uzv-1 tenasüle yerleşdirdikden, diğer ucunu da oturağın içerüsine sokdukdan sonra, düşmemek üzre, çocuğun kasıkları üzerine 'diz yasdı̆̆g' namında küçük yasdık koymak ve ayakları ile kollarını beşiğin yanlarına merbut 'bağırdak' denilen uçları deynekli bağlarla sımsıkı sarub bağlamak da meri olan adatdandır.” Sihhatnüma-i Nevzatdan Kundak-BeşikEmzik, 31-33.

17 Krş. 'İstanbul'da müstamel bir nevi beşik : Berceau turc perfectionné', Sihhatnüma-i Nevzatdan KundakBeşik-Emzik, 33 (Şekil 48).

18 Dr. Besim Ömer, Anne Olacaklara ve Annelere: Çocuk Yetiştirmek - Püerikültür (İstanbul, Ahmet İhsan Matbaası, 1930); Dr. Besim Ömer Akalın, Türk Çocuğunu Nasıl Yaşatmalı ? 2. Püerikültür: Sağlam ÇocukSağlam Nesil-Sağlam Irk (İstanbul, Ahmet İhsan Basımevi, 1939). Ayrıca, İhsan Hilmi Alantar, Püerikültür: Ferdi ve İçtimai Çocuk Hıfzıssıhhası (1931); Püerikültür: Tek Tek ve Toplu Çocuk Hijyeni (1938); Püerikültür: Kişisel ve Sosyal Çocuk Să̆lı̆̆ Bilgisi (1944, 1949).

19 "Bu son günlerde Paris Mekteb-i Tıbbiyesinin en büyük hocalarından [Adolphe] Pinard'ın kızlar mektebinde okutduğu Çocuk Büyütmek Dersleri [Éducation morale et pratique dans les Écoles de filles; La Puériculture du premier Âge,parleDrA.Pinard,Paris,A.Colin, 1904]...”'BesimÖmerPaşa,ÇocukBüyütmek(İstanbul,1320/1904) 3. Dr. Besim ÖmerAkalın, Çocuk Büyütmek adıyla yayımladığı kitapların çeviri olduğunu açıklamaktadır: "19021903 yılında Paris’te hemen ilk defa olarak Tıp Fakültesi Doğum Seririyatı Profesörü hocam Pinard, ilk defa kız mektebinde püerikültüre dair konferanslar vermişti. Bu konferanslar 1904 tarihinde kitap suretinde çıkarıldı. Ben de hemen otuz yıl evvel bu kitabı tercüme edip Çocuk Büyütmek adile ve memleketimize ait bazı şekiller ve resimler ilavesi bastırdım. Kitabın iki basısı vardır.” Besim Ömer Akalın, Türk Çocuğu Yaşamalıdır (İstanbul: Ahmed İhsan Basımevi, 1936), ekleme [s. i]. 
s. 3 [118] tatbik-i hareket olunacağına : olacağına

tevakki ve tahaffuz-1 tedâvîye tevessülden akdem ü evla idüğ̈̈:

tevakki ve tahaffuz tedâvîye tevessülden akdem ve evla idüğü

s. 14 [107] sıkça sarılır : sıkıca sarılır

s. 16 [105] alıkonularak : alına konularak...

s. 25 [96] Kundak ayakları çok taşıdığıdan vücudun kısm-1 esfelini yeniden sarmak üzere... Doğrusu: Kundak ayakları çok taşdığında...

(Les langes dépassant de beaucoup les pieds... Auvert \& Pingat, s. 18.)

s. 35 [98] mecbur kılınmış : mecbur kılmış

s. 49 [72] beşik de sivrilmekde imiş. Doğrusu: büyüdülmekde imiş.

\section{Çeviri ve Sadeleştirme}

s. 64 [57] Şekil 49. İstanbul'da müstamel beşik.

Doğrusu: İstanbul'da müstamel sübek !

(Çizimde beşik değil, kundaklı erkek ve kız bebekler için kullanılan iki sübek/sibek ve bir lazımlık/oturak görülmektedir.)

s. 65 [56] kepek yolu massederek

Doğrusu: kepek bevli massederek

s. 68 [53] ebeveyn çocuklarını neharen burada bırakır.

Sadeleştirme: Anne ve baba çocuklarını geceleyin burada bırakır.

Doğrusu: Anne-babalar çocuklarını gündüz burada bırakır.

s. 75 [75] cidayet : ciyadet

s. 85 [36] fi yevmina haza kullanıldı̆̆ı kadar bir zaman istimal olmamışdır.

Doğrusu: fi yevmina haza kullanıldığı kadar hiçbir zaman istimal olmamışdır.

s. 88 [33] serli : sırli

S. 88 [33] (Şekil 90, s. 86[35]) Çeviri ve sadeleştirme: gurreden mamul desti²0

Doğrusu : gre'den mamul desti (gre, Fr. grès, kumtaşı; pot de grès). ${ }^{21}$

20 Gurre (Ar. i), anne rahmindeki çocuğun (cenin) düşürülmesinden dolayı ödenmesi gereken tazminat; atın alnındaki beyazlık; bir şeyin başlangıcı ve göze ilk çarpan kısmı; bir şeyin en iyisi, en değerlisi; yüzdeki güzellik ve parlaklık; beyaz köle ve cariye gibi manalara gelir, bkz. TDV Íslam Ansiklopedisi, c. 14 (İstanbul, 1996) 211-212 (Muhsin Koçak).

21 Sihhatnüma-i Nevzatdan Kundak-Beşik-Emzik kitabında aynı emzik için (s. 57, Şekil 104) "Çokdanberi 
s. 94 [27] temiz alınması. Doğrusu: temizlenmesi

s. 98 [23] 1 rk ve neslimin... neslimizin

\section{Yanlış okunan Fransızca isimler}

Özel isimler, kontrol edilmeden, yanlış transkripsiyonlarla verilmiştir.

s. 11 Sokslet cihazı: Soxhlet cihazı [Soxhletkocher]

Yazma :

s. 21 [100], De Clauze : Vaucluse

s. 22 [99] Turenne: Touraine; Lanne : Aine (l’Aine)

s. 24 [97] bürüle: bourrelet

s. 40 [81] Butuküdus kadın: Butocudos

s: 54 [67] Bonnes: Beaune

s. 60 [61] Saint-Paul de Lyon: Saint-Pol-de-Léon

s. 72 [49] Yvon: Yonne

\section{Sadeleştirme hataları}

s. 9 (Şekil) Çocuk arabası : İstanbul'da beynelahali müstamel çocuk arabası ${ }^{22}$

\section{Yazma :}

s. $1[120]$

Çeviri: Mekteb-i Tıbbiye-i Şâhâne Fenn-i Vilâde Mu'allimi... Doktor Kolağası Besim Ömer Kulları

Sadeleştirme: Mekteb-i Tıbbiye Kadın Doğum Hocası... Dr. Besim Ömer²3

Doğrusu: Mekteb-i Tıbbiye-i Şahane Doğum Bilgisi Profesörü... Doktor Kolağası Besim Ömer Kulları

s. 4 [117] Çeviri: sâye-i inâyet-vâye-i cihânbânîde Paris’e i‘zâm buyurulduğumdan... : Sadeleştirme: II. Abdülhamid tarafından Paris’e gönderilmiştim.

s. 11 [110] Çeviri: ilk insanlar çocuklarını... bırakmalı idiler.

23 Başka yerde, okul adı verilmeden: '1891 yılında İstanbul'a dönünce Serîriyât-1 Vilâdiye (Doğum Kliniği) muallimi (profesör) oldu’ (Giriş, s. 12). 


\section{Sadeleştirme: bırakmadılar}

s. 33 [88] Çeviri: azasını zabt edemeyen çocuğu...

Sadeleştirme: organlarını kontrol edemeyen

Doğrusu: kol ve bacaklarını (ekstremitelerini)

s. 48 [73] Kabail: topluluklar. Doğrusu: kabileler

s. 51 [70] Çeviri: Uğur beşiğin üstünde olan ufki direkdir.

Sadeleştirme: Uğur beşiğin üzerinde olan yatay uzun sopadır. (ufki: yatay eksik)

s. 94 [27] Çeviri: uzvi tohumlar...

Sadeleştirme: organizmalar... doğrusu: mikro-organizmalar

s. 95 [26] Çeviri: zeytuni bir şekilde olan şişenin

Sadeleştirme: zeytin rengindeki bir şişenin...

Doğrusu: zeytin biçiminde olan bir şişenin

s. 96 [25] Çeviri: meme başlarındaki sû-i teşekkülde

Sadeleştirme: meme ucunun emzirmeye uygun olmayış1...

Doğrusu: memebaşlarındaki yapı bozuklukları (malformasyon)

s. 97 [24] Çeviri: hammâm-1 maride.

Sadeleştirme: man (?) banyosunda. ${ }^{24}$

Doğrusu: mari banyosu, benmari (bain-marie)

\section{Besim Ömer'in yanlışları}

Yazma:

\section{s. $75-76$ [46-45]}

Çeviri: ebeveynin kurtulmasını arzu eylediği çocukları

Sadeleştirme: anne ve babanın kurtulmasını arzu ettikleri çocukları

Doğrusu: ebeveynin kurtulmak veya def etmek istediği çocukları

(des enfants dont les parents voulaient se défaire Auvert \& Pingat, s. 58). ${ }^{25}$

24 İndekse de 'man banyosu' (s. 18) olarak geçen isim, girişte benmari (hammam-1 mariyye) biçiminde yazılmıştır (s. 11, resim). Kitapta bu cihazın adı için - biri yanlış - üç farklı yazım vardır.

25 Besim Ömer bu cümleyi Sıhhatnüma-i Nevzatdan Kundak-Beşik-Emzik adlı kitabında düzeltmiştir: "Kadından ve erkekden bazı kimseler var idi ki, ebeveynin başlarından atmak istedikleri çocukları toplayarak bir ücret mukabilinde civardaki hastahaneye veya sütninelere getirirlerdi" (s. 42). 
s. 63 [58]

Varek otu

Doğrusu: Fr. Varech (Fucus vesiculosus L.) denizyosunu, kahverengi algler.

S. 13 [108]

Besim Ömer'in bir tarih hatası: "Bartholin nâm zât on beşinci asr-1 mîlâdîde neşreylediği bir kitabda..."

Besim Ömer'in alıntı yaptığı hekim Thomas Bartholin (1616-1680) 15. yüzyılda değil, 17. yüzyılda yaşamıştır.

\section{Ve unutulan dipnotlar}

Giriş metninde 6 dipnot olduğu halde, 6. dipnotun metni yoktur (s. 14). Yazmanın çeviri ve sadeleştirme metinlerinde 4 ile 45 'e arasında numaralandırılmış dipnotlar olduğu halde, ${ }^{26}$ kitapta hiçbirine ait açıklama yapılmamıştır.

\section{Doğururken ve Doğurduktan Sonra}

Dr. Besim Ömer Akalın'ın Doğururken ve Doğurduktan Sonra adlı kitabının yeni yayımının başlığında basım tarihine Hicri 1320 / Miladi 1902-1903 olarak yer verilmiştir. Buna karşılık, kitabın tanıtımının yapıldı̆̆ı İkinci Bölümde: “Doğururken ve Doğurduktan Sonra adlı eser Besim Ömer (Akalın) Paşa tarafından yazılmış ve 6 Ekim 1904 tarihinde İstanbul'da Ahmed İhsan Matbaası'nda yayınlanmıştır" bilgisi verildikten sonra, günümüzün “Tıp doktorları 1904 tarihinde yazılan bu eseri...” incelemeye çağırılmaktadır. Böylece, kitabın orijinalindeki 1320 tarihinin Hicri değil, Rumi olduğu anlaşılarak, kitabın başlığındaki tarih düzeltilmiş olmaktadır. ${ }^{27}$ Kitabın (1.) basımı için verilen izin belgesi de 16 Nisan 1904 tarihini taşımaktadır. ${ }^{28}$

Çeviriyazısı hazırlanan Doğururken ve Doğurduktan Sonra için verilen bibliyografik bilgi şöyledir: "Eserin girişinde yer alan ilk 3 sayfa numaralandırılmamıştır. Bunlar eserin kapak sayfalarıdır. Daha sonra eser 1. sayfadan başlayarak numaralandırılmıştır. Toplam 144 sayfadır”. Ayrıca, çevirinin kitabın "yeşil bir cild ile kaplanmış olup, cild kapağında da eserin ve yazarın ismi bulunan” bir kopyasından yapıldığı belirtilmiştir (s. 6). Ne var ki, bu

26 Yazma, 15, dn 4 (çeviri ve sadeleştirme: Turpin); 45 [76], dn 15 (çeviri ve sadeleştirme: Virjini Tarihi); 46 [75], dn 17 (sadeleştirilme: Chateaubriand Amerika'ya dair yazdiğ seyahatnamesinde); 46 [75], dn 19 (çeviri: Tesalya); 47 [74], dn 20 (sadeleştirme: Fonssagrives); 53 [68], dn 24 (sadeleştirme: Merkür); 80 [41], dn 34 (sadeleştirme: Demosten); 84 [37] dn 37 (sadeleştirme: Gaulois); 89 [32], şekil 99, dn 43 (Mathieu); 89 [32], şekil 101, dn 45 (Robert).

27 Kitabın tam künyesi: Besim Ömer Akalın, Doğururken ve Doğurduktan Sonra (İstanbul, Matbaa-i Ahmed İhsan, 1320 [1904]), [iv+] $160 \mathrm{~s}$ : resim, tablo; 14x20 cm. (EHT, ön ve arka kapak resmi mevcuttur) [Atatürk Üniversitesi Merkez Kütüphanesi, Seyfettin Özege Bölümü 2955 SÖ 1320].

28 T.C. Cumhurbaşkanlığı Devlet Arşivleri Başkanlığı Osmanlı Arşivi (BOA), MF.MKT 797, 77. 13 Nisan 1320/10 Safer 1322 . 
kitabın orijinali 160 sayfadır ve yayımlanan çeviri metninde 144 ile 160. arasındaki sayfalar eksiktir. Çeviriyazıyı hazırlayan(lar) kitabın künyesini kontrol etmedikleri gibi, ellerindeki kopyada son formanın eksik olduğunu da fark etmemişlerdir !

Doğururken ve Doğurduktan Sonra kitabının çevirilmeyen bölümleri:

[12. Bölüm] Çocuğu Memeden Kesmek (s. 149-151)

[13. Bölüm] Anadan Doğma Zayıflık (s. 152-157)

Yeni yayının başındaki kısa sunuşta, "Bu eser, sadece tıp tarihi alanında çalışanlar için değil, aynı zamanda Kadın [Hastalıkları ve] Doğum sahasında çalışanlar için de önemli bir kaynak teşkil edecektir” denilirken, kitabın yenidoğan ve çocuk sağlığıyla olan ilgisi gözardı edilmiştir. Daha da önemlisi, sunuşu yazan kişinin Dr. Besim Ömer'in "Yenidoğan çocukların, hele bizde yüzde seksan kadarı daha ilk yaşlarını bitirmeden telef olub gidiyorlar" (s. 8) sözlerinden hiç etkilenmemiş görünmesidir ! ${ }^{29}$

Birinci Bölümde yer alan, "Paris'deki öğreniminin ardından yurda döndüğünde rütbesi generalliğe yükseltilen Besim Ömer... 1892'de saraydan gizlice bir doğum kliniği açmıştır” cümlesi çelişkilidir. Dr. Besim Ömer Bey, padişahtan - bir biçimde - izin alarak 'viladethane'sini açtı̆̆ı tarihte henüz Binbaşıdır. ${ }^{30}$ Doğururken ve Doğurduktan Sonra kitabının diliçi çevirisinde yapılan yanlışlar ise, çevirinin hangi dile yapıldığını sorgulatacak düzeydedir. Birkaç örnek vermek gerekirse,

[s. i] Mütabbipler: mütetabbibler

\section{s. ii [13/162] Doktor Besim Ömer'in bazı asar-ı matbuası}

\section{Emraz-ı Tüsa 'i. Doğrusu: Emraz-ı Nisa`}

Kendini Bil - İzai ‘ ve Íchizai ‘ Bedenden Bahisdir

Doğrusu: Kendini Bil-Aza ve Echize-i Bedenden Bahisdir

Dokuzda Banyo - Su ile Tedavi. Doğrusu: Denizde Banyo - Su ile Tedavi

Gebelik ve Bebelikde Tedabir. Doğrusu: Gebelik ve Gebelikde Tedabir

29 Mehmet Füzün, 'Sunuş', Doktor Besim Ömer Paşa, Doğururken ve Doğurduktan Sonra (H. 1320/M. 19021903), yay.haz. Türkmen Töreli (İzmir, Dokuz Eylül Üniversitesi yay., 2014) içinde [s.v].

30 Doktor Besim Ömer, Nevsal-i Afiyet [I. c.], (İstanbul: Alem Matbaası, Ahmed İhsan ve Şürekası, 1315/1899), 283 (Ebelerimiz): "Gerçi saye-i hazret-i Padişahide Mekteb-i Tıbbiye-i Şahane civarında sekiz-dokuz yataklık bir mahal viladethane ittihaz olunmuş...". Ayrıca bkz., Ayten Altıntaş ve Oğuz Ceylan, "Viladethane," Tip Tarihi Araştırmaları sayı 14 (2006): 329-339. 


\section{[1. Bölüm] Başlamazdan evvel}

s. $1[17 / 166]$... sebeb-i rahatı ve türküsüdür : sebeb-i rahat ve terakkisidir.

...büyük bir doğuşda az çok yaralanmış bir mecruha : büyük bir döğüşde...

s. 2 [18/167] zor ve ağır bakılı bir işdir : zor ve ağrıklı bir işdir.

s. 4 [19/168] lutf-ul ehlidir : lutf-i ilahidir.

gözleri o günde : gözleri önünde

katre-i geriyemizi : katre-i giryemizi

melek'ül-isyanesi : melekü's-siyanesi

S. 5 [20/169] beşik hazırdır : beşik-i hazırdır

hakim ebeler : hekim ebeler $^{31}$

s. 7 [22/171] meşluk : meşkuk

melus : mülevves

zürriyet altının : zürriyet aletinin

s. 8 [23/172] hastalık tahammüllerine : hastalık tohumlarına

s. 9 [24/173] sütlü anların, dakikaların : sütlü unların, dakiklerin

o çocuklara yarelere : açtıkları yaralara

s. 77 [62/226] Resimalt1

Çocuğun yürek evirmesinin dinlenmesi: Çocuğun yürek [v]urmasının dinlenmesi

[11. Bölüm ] Emzirme - Hem Meme Verme Hem de Emzirme

S. 131 [146/294] sereçeli : sıracalı

s. 132 [147/295] sıyırıp : singirmek [sindirmek]

sütü 73 dereceye kadar 1sitılmaya : sütü $\mathbf{3 7}$ dereceye kadar 1sitılmağa

s. 133 [148/296] (Resimaltı) hastalık tanımları : hastalık tohumları

s. 135 [150/298] misal bir fincan su konulur: mesela bir fincan süte iki fincan su konulur

31 Doğum uzmanı hekim, tabib-i müvellid, lavta. 
s. 138 [153/301] "Lemyanid" denilen emzikler : [biberon] Limande

s. 139 [154/302] Karbonat du sud (fahmit süt) : fahmiyet-i sud (sodyum karbonat)

s. 140 [155/303] Havacem ma'allim büdan icad itmiştir: Hocam muallim Budin icad etmişdir. $^{32}$

"Sütlük - galaktufur" : Galaktofor (Galactophore)

s. $141[156 / 304]$ verem tanımı : verem tohumu

s. 142 [157/305] üç çarik saat: çaryek (çeyrek) saat

savurmasıly: sovumasile

s. $143[158 / 306]$ suksulat aleti : Soxhlet aleti

s. 144 [159/307] Suksulat, budan, jatil : [Franz Ritter von] Soxhlet, [Pierre] Budin, Gentile

Diliçi çeviri 11. Bölümde, s. 144 [159]:

"Kapak hizmetinde kullanılan lastiklerin biçimini adı yahûd alt yüzü memeli bir kars yahud maden suyu şişelerinin ağızlarına konulan kolay başlık gibidir” cümlesiyle sona ermektedir.

(Doğrusu: Kapak hizmetinde kullanılan lastiklerin biçimi adi yahud alt yüzü memeli bir kurs, yahud maden suyu şişelerinin ağızlarına konulan kalay başlık gibidir.)

Dr. Besim Ömer Akalın'ın Doğururken ve Doğurduktan Sonra kitabının metni ise, 145. Sayfada: "Bu aletler yok ise adi pul şişelerle de sütü bu yolda kaynatmak mümkündür..." cümlesiyle (157. sayfaya kadar) devam etmektedir. Besim Ömer, sözlerini kendi deneyimini anlatarak tamamlar:

“Eksik doğan çocukların... emmeğe mecali yoksa, ağzına kaşık veyahud emzik ile süt akıtmağa lüzum varsa, midesine boru [gavaj] itdirmeğe çalışmalıdır. Bu yoldaki tedabir ile İstanbul'da gerek Viladethane'de gerek başka yerlerde, aile içlerinde beş-altı zayıf çocuğu kurtarmağa muvaffak olduk. Bugün onlar da herkes gibi, güzel güzel duruyorlar." ${ }^{\prime 3}$

32 Dr. Pierre Budin, 1896'da Besim Ömer'i İstanbul'da ziyaret etmiştir 'Muallim-i şehir Budin'in... geçen sene memleketimize seyahatlerinde şifahen vuku bulan tavsiyesine binaen...' Doktor [Pierre-Constant] Budin, Seririyat-l Viladiye Dersleri, mütercimi Doktor Besim Ömer (Mekteb-i Tibbiye-i Şahane'de Fenn-i Vilade ve Ebeler Muallimi Kaimmakam) (İstanbul: Mekteb-i Tıbbiye-i Şahane Matbaası, 1313 [1897]), iii (İfade). Dr. Besim Ömer Bey, Budin'in kitabını Türkçeye çevirmiş olmasına karşın, "Doğum dersini Fransızca Auvard'ın klasik doğum kitabından güzel bir ifade ile anlatır[dı]," Tevfik Sağlam, Nasıl Okudum, 2. bs. yay.haz. Hüsrev Hatemi ve Aykut Kazancıgil, (İstanbul: İ.Ü. Cerrahpaşa Tıp Fak. yay., 1981), 77.

33 Besim Ömer (Cemiyet-i Tibbiye-i Osmaniye azasından ve Mekteb-i Tibbiye-i Askeriye'de Fenn-i Vilade 


\section{III. Üniversite Yayıncılığı içinde Yeni (Tıpkı-)Basımlar}

Üniversite yayınları, üniversitelerde üst makamın seçim ve oluruyla yapılan, genellikle eğitsel yayın dizilerinden oluşmaktadır. Üniversite yayınevleri ise, adını taşıdıkları üniversiteye karş1 akademik ve yükümlülükleri olan özerk kuruluşlardır. Yayınevlerinin editörlük yanında, nitelikli yayıncılığın gerektirdiği belirli uzmanlık kurulları olur: metin ve dil inceleme, yazım denetimi, teknik sekreterlik, istatistik sağlaması, vb. Eski Harfli Türkçe (EHT) tıbbi metinlerin diliçi çevirisini içeren yayınlar özelinde, yayını hazırlayanların, ister bir üniversite adına, ister bir üniversite yayınevi için olsun, çevirilen metinin konusunu, kavramlarını ve dönemin yerli ve yabancı literatürünü bilen, metin içinde geçen yabancı dillerdeki isim, terim, reçete ve formülleri çözümlerken, bunların değişik - çoğu zaman da yanlış - yazılışlarını fark edebilecek kadar deneyimli danışmanlardan yararlanması gerekir.

Ele aldığımız kitaplardan birincisinde: Dr. Besim Ömer'in elyazmasının yeni yayımında çevirmen ve editör olarak aynı ismin verildiğini görüyoruz. İkinci yayında ise, bir editör adı yoktur. Kitapların künyelerindeki bu açıklamalar, çeviriyazıların belirli bir denetimden geçmediğini göstermektedir. Yukarıda verilen örnekler bunu kanıtlamaktadır. Besim Ömer Bey, olağanüstü verimli, araştırıcı bir yazar, disiplinli bir klinisyen, yönetici ve örgütçü idi. Kitaplarının diline büyük özen gösterirken okur profilini de gözetirdi. Biyografilerinde fazla yer verilmeyen özel ve siyasal yaşamı onun karakter zenginliğinin ışıklı parçalarıdır. Darülfünun Emini Muallim Doktor Besim Ömer Bey'in kitaplarının, üniversite yayınları arasında bu halleriyle yeniden yayımlanmasından mutluluk duyar mıdı ? Kuşkuluyuz.

Muallim Muavini olub Paris'de ikmal-i ameliyat ile meşgul, Kolağası), Zaylf ve Vakitsiz Doğan Çocuklara Edilecek Takayyüdat: Küvöz - Gavaj (İstanbul: Mahmud Bey Matbaas1, H. 1306/1888) [Fransızca kapak: Soins à Donner aux Enfants Nés Faibles et Avant Terme: La Couveuse et Gavage par B. Omer, (Constantinople: Imp. Mahmoud Bey, 1888)] (12x18 cm., 107 s.). Besim Ömer, bu kitabında Paris'de 1888'de toplanan Tüberküloz Kongresine de katıldığını bildirmektedir (s. 81, dn): "Paris'de milel muhtelife etibbasından teşekkül idüb benim de acizane aza bulunduğum verem kongresinde (Congrès de la tuberculose)..."; Congrès pour l'Étude de la Tuberculose chez l'Homme et chez les Animaux; Informations et Documents divers; 1. Session du 25 au 31 juillet 1888 à Paris: Informations et Documents divers (Paris, G. Masson, 1888), 11 (Liste des membres du Congrès). https://curiosity.lib.harvard.edu/contagion/catalog/36-990074555810203941 Dr. Besim Ömer Akalın'ın veremle ilgili çalışmaları için, bkz. Emine Ö. Evered ve Kyle T. Evered, "Dispensary, home, and 'a women's army': Framing tubercular geographies and gender in late Ottoman Turkey," Journal of Historical Geography 68 (April 2020): 33-43. 